\title{
Coexistent lung adenocarcinoma and giant cell carcinoma in different lung lobes of the same patient
}

\author{
Yan Li, Shiping Song, Chang-qing Bai, Xiao-bing Li, Wen-kai Niu, Xue-yi Shang \\ Department of Respiratory Diseases, the Affiliated Hospital of the Academy of Military Medical Science, Beijing, China \\ Yan Li and Shiping Song contributed equally to this article.
}

Contemp Oncol (Pozn) 2015; 19 (2): 163-165 DOI: $10.5114 /$ wo.2015.51422

Lung giant cell carcinoma is a specific type of lung carcinoma characteristically associated with a highly aggressive clinical behaviour. This tumour is usually defined as a malignant epithelial tumour with large nuclei, prominent nucleoli and abundant cytoplasm without the features of squamous cell, small cell or adenocarcinoma. Lung giant cell carcinoma, belonging to the group of pleomorphic carcinoma, occurs mainly in men who smoke heavily [1]. It is not routinely treated surgically, owing to the fact that it is metastatic at the time of diagnosis, but resection or radiation have been suggested to prolong survival time. We experienced a rare case of lung giant cell carcinoma accompanied by lung adenocarcinoma in a different lobe of the same patient.

A 64-year-old man presented to our hospital with a seven-month history of shortness of breath. Smoking history was 40 cigarettes per day for 30 years. Physical examination and routine blood examination showed normal. Plasma levels of tumour markers were as follows: squamous cell carcinoma antigen, $4.1 \mathrm{ng} / \mathrm{ml}$ (normal range, 0 to $2.0 \mathrm{ng} / \mathrm{ml}$ ); cytokeratin fragment, $2.62 \mathrm{ng} / \mathrm{ml}$ (normal range, 0 to $3.5 \mathrm{ng} /$ $\mathrm{ml}$ ); carcinoembryonic antigen, $70.4 \mathrm{ng} / \mathrm{ml}$ (normal range, 0 to $4.3 \mathrm{ng} / \mathrm{ml}$ ); neuron specific enolase, $11.63 \mathrm{ng} / \mathrm{ml}$ (normal range, 0 to $17 \mathrm{ng} / \mathrm{ml}$ ); CA19-9, $47.52 \mathrm{U} / \mathrm{ml}$ (normal range, 0 to $27 \mathrm{U} / \mathrm{ml}$ ) and pro-gastrin-releasing peptide, $24.3 \mathrm{pg} / \mathrm{ml}$ (normal range, 0 to $46.0 \mathrm{pg} / \mathrm{ml}$ ). Arterial blood gas analysis yielded the following: $\mathrm{pH}=7.42, \mathrm{PO}_{2}=74 \mathrm{~mm} \mathrm{Hg}, \mathrm{PCO}_{2}=40$ $\mathrm{mm} \mathrm{Hg}$ and oxygen saturation of $96 \%$.

The chest CT showed a ca. 2.5-cm soft-tissue density in the right upper lung field (Fig. 1A, B). Bronchoscopy was performed, revealing a neoplasm existing in the bronchial lumen of the left lingular segment, but normal mucosa in the right upper bronchi. By bronchoscopy, biopsy of the neoplasm revealed giant cell carcinoma in left lingular segment, with immunohistochemical characteristics positive for pan-cytokeratin and thyroid transcription factor 1 (TTF-1), weakly positive for vimentin and S-100 protein, and negative for desmin, chromogranin A, synaptophysin, P63 and CD68 (Fig. 2). Ultrasound-guided percutaneous lung biopsy of the node in the right upper lobe exhibited a poorly differentiated adenocarcinoma with immunohistochemical characteristics positive for cytokeratin 7 and TTF-1, and negative for cytokeratin 17 (Fig. 3). Metastatic disease was detected by brain CT, abdominal CT and bone scan, but the patient did not present with metastasis.

At this time, the case was diagnosed as coexistent lung adenocarcinomaintherightupperlungfieldand giantcellcarcinoma in the left lingular segment. Subsequently, the patient received radiotherapy in the bilateral upper lobes with a linear accelerator (6 MV). The field size of radiotherapy included the bilateral upper fields and mediastinal lymph node, and was treated with 2 Gy every day on a schedule of five fractions per week. The total dose was 64 Gy. At the same time as radiotherapy, cisplatin $50 \mathrm{mg}\left(30 \mathrm{mg} / \mathrm{m}^{2}\right)$ was administered weekly as a sensitizer of radiation. After radiotherapy, chest CT imaging revealed no change to the node in the right upper lobe, but the bronchial lumen of the left lingular segment became unobstructed by bronchoscopy (Fig. 4A, B). Subsequently, the patient underwent chemotherapy consisting of intravenous cisplatin $140 \mathrm{mg}\left(75 \mathrm{mg} / \mathrm{m}^{2}\right)$ on the $1^{\text {st }}$ day and vinorelbine $40 \mathrm{mg}\left(25 \mathrm{mg} / \mathrm{m}^{2}\right)$ on the $1^{\text {st }}$ and $8^{\text {th }}$ days. The treatment was to be repeated every 21 days. After two chemotherapy cycles, the nodular shadow in the right upper lobe remained unchanged. Bronchoscopy was performed, and the bronchial lumen of the left lingular segment remained unobstructed. After ten months the patient died of respiratory failure because of obstructive pneumonia in the right upper lobe.

\section{Discussion}

Three important issues arise from this case. The first important point is whether or not giant cell carcinoma is an entity unto itself, or a dedifferentiated adenocarcinoma; opinions in the literature are mixed. In a histopathological examination of 46 cases by Attanoos et al. [2], the cases that were called giant cell carcinoma did not have an association between prognosis and the extent of tumour giant cell formation, and were not found to have a particularly adverse prognosis when compared with other non-small cell lung carcinomas. In the end, they suggested that the term giant cell carcinoma should not be used for any carcinoma with a predominant component of pleomorphic multinucleate cells. The presence of tumour giant cells does not highlight a more aggressive tumour type. But the ultrastructural evidence supports a diagnosis of giant cell carci- 

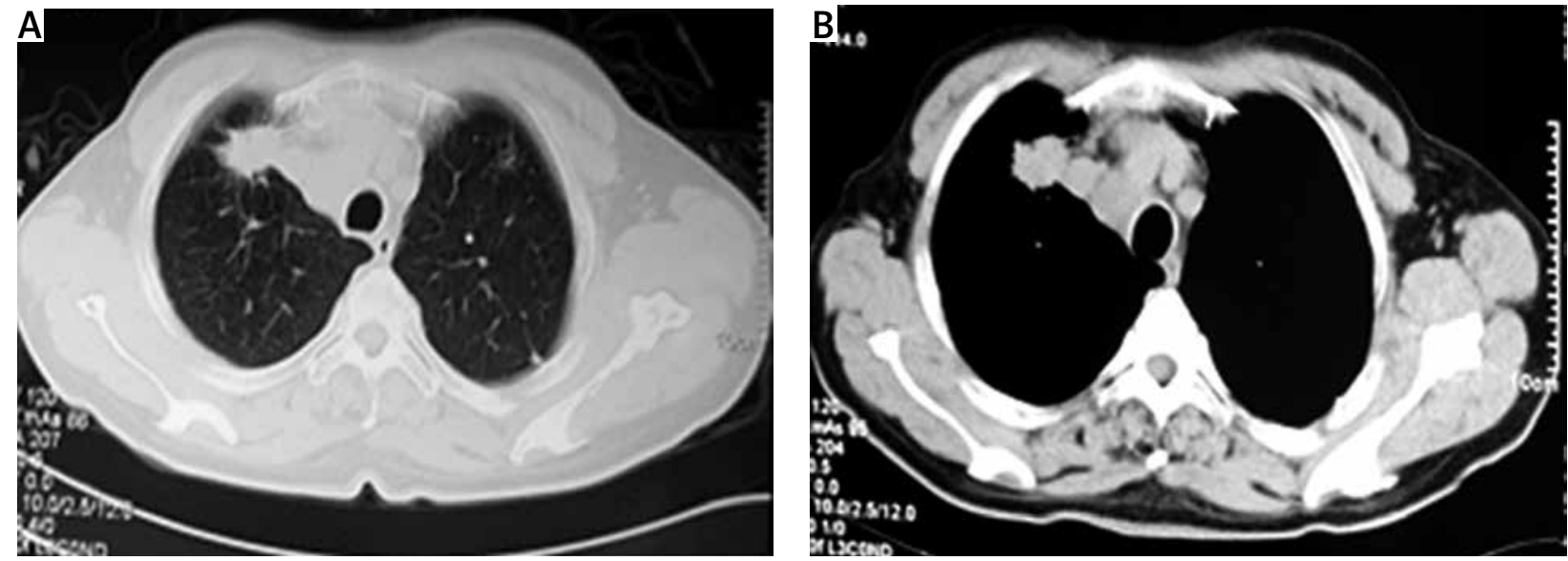

Fig. 1. A) CT image showing nodular shadow in right upper lobe obtained from lung window. B) Nodular shadow from mediastinal window settings

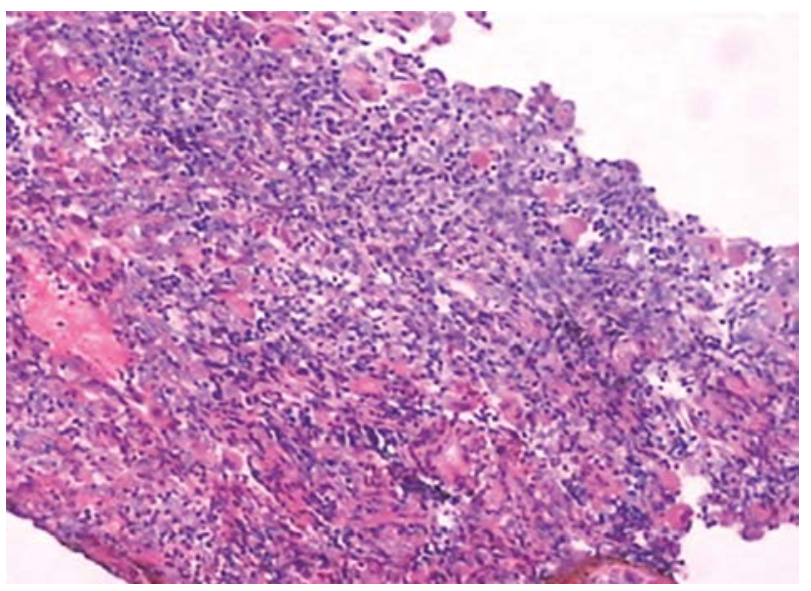

Fig. 2. Pathologic findings of the tumour obtained from biopsied neoplasm. The tumour was diagnosed as giant cell carcinoma. HE, magnification 100x
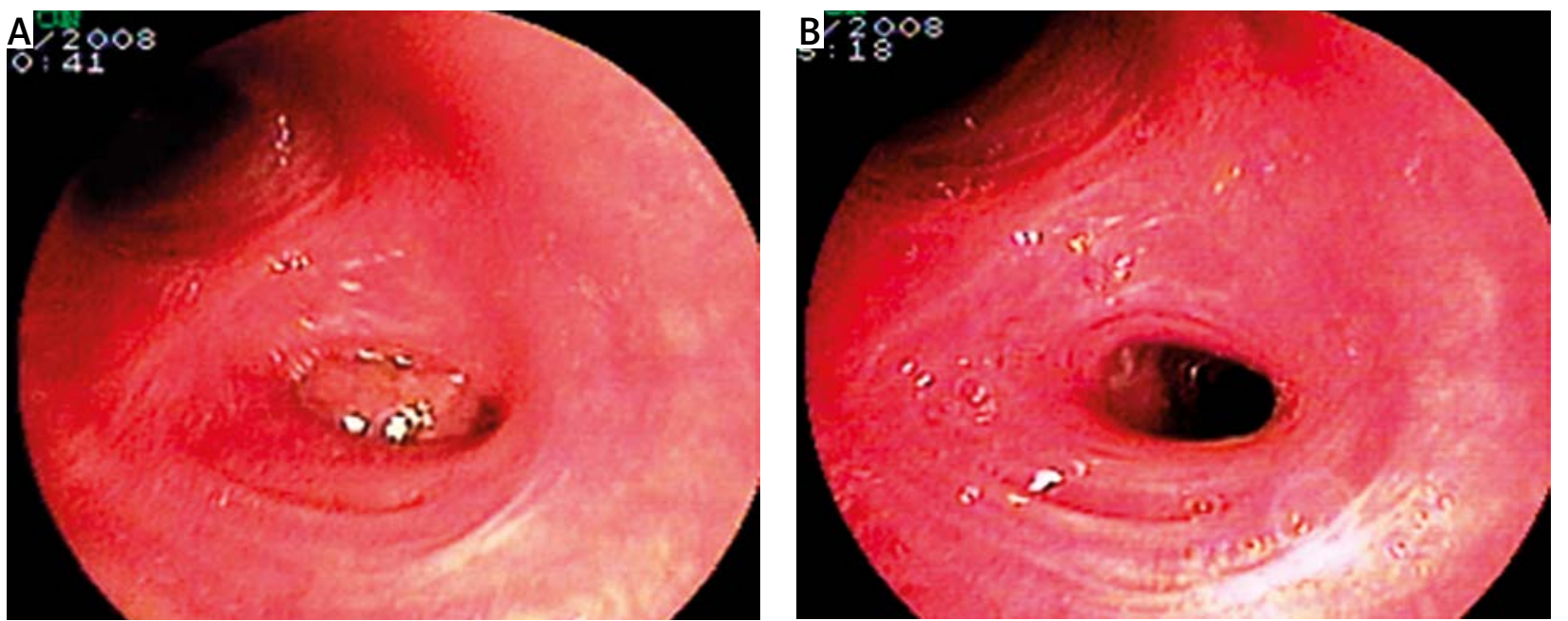

Fig. 4. A) Neoplasm was discovered by bronchoscopy in the left lingular segment. B) The neoplasm of bronchial lumen in the left lingular segment disappeared after radiotherapy

noma as a separate entity. In a study of nine cases by Wang et al. [3], giant cell carcinomas were characterized by abundant ribosomes, poorly developed Golgi apparatus, and scanty aggregation of endoplasmic reticulum - all of which are features reflecting the rapidly proliferating nature of

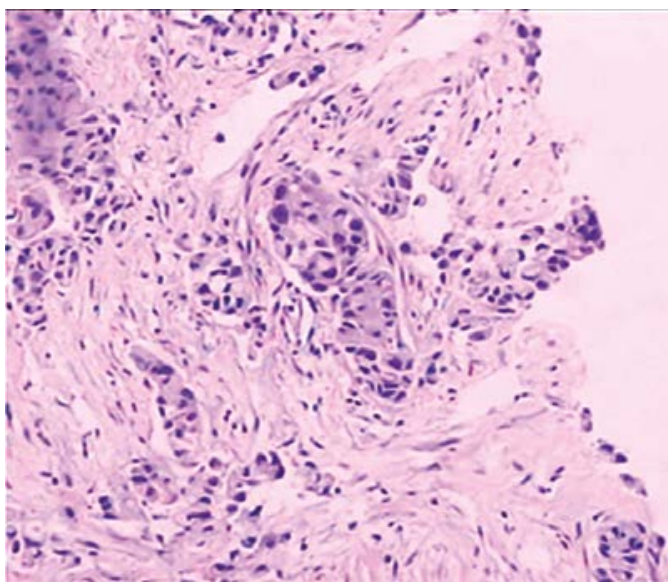

Fig. 3. The tumour was diagnosed as adenocarcinoma. HE, magnification $100 x$ 
The second important point is the imaging characteristics of giant cell carcinoma. According to Rossi et al. [4], in a study of 75 cases of pulmonary carcinoma, pleomorphic carcinoma presented as a large, frequently peripheral, necrotic mass that mainly involved the upper lobes. In a study of 78 cases, by Fishback et al. [5], of pleomorphic (spindle cell and giant cell subtype) carcinoma of the lung, $65 \%$ of the tumours were located in the upper lobes and $60 \%$ of the tumours were peripheral masses. According to Kim et al. [6] in a study of 10 cases of pleomorphic carcinoma of the lung, the tumours also preferentially manifested as large peripheral lung neoplasms. However, the CT feature of our patient was negative in the left upper lobes, but the neoplasm was occasionally observed by routine bronchoscopy. The tumour was an endobronchial growth and was diagnosed by bronchoscopic biopsy. This is the first report to our knowledge.

The third important point is pleomorphic (spindle cell and giant cell subtype) carcinomas of the lung are generally believed to be more aggressive and have a poorer prognosis than ordinary lung carcinomas. To our knowledge, no statistical analysis has been reported, except for the report by Fishback et al. [5]. They reported that tumour size $>5 \mathrm{~cm}$, a clinical stage $>$ stage I and lymph node involvement shortened patient survival significantly. In addition, in a recent study by Hountis et al. [7] there was no significant difference between the prognosis of patients with sarcomatoid carcinoma and that of patients with non-sarcomatoid, nonsmall cell carcinoma of the lung. Regarding the treatment of giant cell carcinoma, previous reports have indicated that an aggressive operative management is the mainstay of the best chances of long-term survival in these unusual tumours of the lung. The role of adjuvant or neo-adjuvant chemoradiotherapy has not proven to be beneficial alone, but they play an important role as an adjunct to standard accepted operative treatment. However, giant cell carcinoma certainly proved to be responsive to radiotherapy, but the adenocarcinoma did not in our experience.

To our knowledge, this is the first reported case of coexistent lung giant cell carcinoma and adenocarcinoma in different lung lobes of a patient, and the two tumours showed different therapeutic response to radiation. In this case, the giant cell carcinoma was an endobronchial growth and the CT feature was negative in the left upper lobe, but the adenocarcinoma showed a about $2.5-\mathrm{cm}$ soft-tissue density in the right upper lung field, and bronchial mucosa was normal by bronchoscopy. Therefore, bronchoscopy should be routinely performed, regardless of the sites of pulmonary masses, to reduce missed diagnoses.

\section{References}

1. Yamamoto S, Hamatake D, Ueno T, Higuchi T, Hiratsuka M, Shiraishi T, Iwasaki A, Shirakusa T. Clinicopathological investigation of pulmonary pleomorphic carcinoma. Eur J Cardiothorac Surg 2007; 32: 873-6.

2. Attanoos RL, Papagiannis A, Suttinont P, Goddard H, Papotti M, Gibbs AR. Pulmonary giant cell carcinoma: Pathological entity or morphological phenotype? Histopathology 1998; 32: 225-31.

3. Wang NS, Seemayer TA, Ahmed MN, Knaack J. Giant cell carcinoma of the lung: A light and electron microscopic study. Hum Pathol 1976; 7: 3-16.
4. Rossi G, Cavazza A, Sturm N, Migaldi M, Facciolongo N, Longo L, Maiorana A, Brambilla E. Pulmonary carcinomas with pleomorphic, sarcomatoid, or sarcomatous elements: a clinicopathologic and immunohistochemical study of 75 cases. Am J Surg Pathol 2003; 27: 311-24.

5. Fishback NF, Travis WD, Moran CA, Guinee DG Jr, McCarthy WF, Koss MN. Pleomorphic (spindle/giant cell) carcinoma of the lung. Cancer 1994; 73: 2936-45.

6. Kim TH, Kim SJ, Ryu YH, et al. Pleomorphic carcinoma of lung: comparison of CT features and pathologic findings. Radiology 2004; 232: 554-9.

7. Hountis P, Moraitis S, Dedeilias P, Ikonomidis P, Douzinas M. Sarcomatoid lung carcinomas: a case series. Cases J 2009; 2: 7900.

The authors declare no conflict of interest.

\section{Address for correspondence}

\section{Yan Li}

Department of Respiratory Diseases

The Affiliated Hospital of the Academy of Military Medical Science No. 8 DongDa Street, Fengtai District

Beijing 100071, China

e-mail:yanlicn@yeah.net

Submitted: 24.05 .2012

Accepted: 28.09 .2012 